\title{
Apolipoprotein E $\varepsilon 4$ Allele Increases Risk for Psychotic Symptoms in Alzheimer's Disease
}

\author{
Kristina F Zdanys', Timothy G Kleiman', Martha G MacAvoy', Benjamin T Black', Tracy E Rightmer', \\ Monique Grey', Katherine S Garman', Rajesh R Tampi', Joel Gelernter ${ }^{2}$ and Christopher H van Dyck ${ }^{*, 1,3}$ \\ 'Alzheimer's Disease Research Unit, Yale University School of Medicine, New Haven, CT, USA; ${ }^{2}$ Division of Human Genetics, Department \\ of Psychiatry, Yale University School of Medicine, New Haven, CT, USA; ${ }^{3}$ Department of Neurobiology, Yale University School of Medicine, \\ New Haven, CT, USA
}

\begin{abstract}
The apolipoprotein $\mathrm{E}(\mathrm{ApoE}) \varepsilon 4$ allele is a well-documented genetic risk factor for sporadic Alzheimer's disease (AD). Its association with psychopathology among AD patients has been the subject of discrepant reports. We aimed to determine whether ApoE $\varepsilon 4+$ and $\varepsilon 4-\mathrm{AD}$ patients exhibit a different risk profile for psychotic symptoms and other behavioral disturbances. The Neuropsychiatric Inventory (NPI) was administered to determine the frequency and severity of psychotic and other behavioral symptoms in a sample of $n=266$ AD patients who had been genotyped for ApoE. Multiple logistic regression models were used to calculate the association between the ApoE $\varepsilon 4$ allele and the presence of psychotic symptoms (delusions or hallucinations). Exploratory analyses were also conducted to determine the impact of disease severity on $\varepsilon 4$ effects and to examine the association between $\varepsilon 4$ and other behavioral symptoms. ApoE $\varepsilon 4$ was significantly associated with psychotic symptoms (odds ratio $(\mathrm{OR})=1.87,95 \% \mathrm{Cl}=1.07-3.29, \mathrm{P}=0.029$ ), adjusting for age, sex, education, and MMSE score. More stringent definitions of clinically significant psychosis yielded similar results. Exploratory analyses suggested that this effect accrued specifically from patients with severe-stage AD and primarily from an association between $\varepsilon 4$ and delusions. The $\varepsilon 4$ allele did not appear to influence the development of most other behavioral symptoms in our sample. In conclusion, AD patients who carry the ApoE $\varepsilon 4$ allele are at greater risk than noncarriers for developing psychotic symptoms, particularly as the severity of their dementia progresses.

Neuropsychopharmacology (2007) 32, I7I - 179. doi: I0. I038/sj.npp. I 30 I |48; published online I2 July 2006
\end{abstract}

Keywords: Apolipoprotein E; Alzheimer's disease; psychotic symptoms; delusions; hallucinations

\section{INTRODUCTION}

The Apolipoprotein E (ApoE) locus on chromosome 19 is the only well-documented genetic risk factor for the development of sporadic AD (Saunders et al, 1993). Among the three major isoforms of $\operatorname{ApoE}(\varepsilon 2, \varepsilon 3$, and $\varepsilon 4)$, the $\varepsilon 4$ allele has been reported to increase an individual's risk of developing $\mathrm{AD}$, and decrease age of disease onset, in proportion to the number of $\varepsilon 4$ alleles present (Corder $e t$ al, 1993; Farrer et al, 1997). The search for phenotypic correlates of $\varepsilon 4$ has included neuropathological studies of the rate of $\beta$-amyloid (A $\beta$ ) deposition (Schmechel et al, 1993; Nagy et al, 1995; Norrman et al, 1995; Gomez-Isla et al, 1996), neurofibrillary tangle formation (Schmechel et al, 1993; Nagy et al, 1995; Norrman et al, 1995; Gomez-Isla et al, 1996), cholinergic markers (Poirier et al,

\footnotetext{
*Correspondence: Dr CH van Dyck, Alzheimer's Disease Research Unit, Yale University School of Medicine, One Church Street, Suite 600, New Haven, CT 065I0, USA, Tel: + I 2037648100 , Fax: + I 203764 8I I I, E-mail: christopher.vandyck@yale.edu

Received 27 December 2005; revised 20 April 2006; accepted 25 May 2006

Online publication: I June 2006 at http://www.acnp.org/citations/ Npp060 10605077//default.pdf
}

1995; Soininen et al, 1995), and medial temporal lobe atrophy (Lehtovirta et al, 1996b; Hashimoto et al, 2001; Basso et al, in press).

The links between the ApoE $\varepsilon 4$ allele and decreased age of $\mathrm{AD}$ onset and increased accumulation of pathological features has prompted the hypothesis that $\varepsilon 4$ may play a role in accelerating the clinical manifestations of the disease. However, that hypothesis has thus far not been supported by the majority of clinical studies, which have shown no effect of ApoE genotype on rate of cognitive decline in AD (eg Farlow et al, 1999; eg Aerssens et al, 2001; Kleiman et al, 2006). However, some investigators have reported that the presence of at least one 84 allele may increase (Craft et al, 1998; Hirono et al, 2003) or even decrease (Frisoni et al, 1995; Stern et al, 1997) the rate of cognitive decline.

Investigators have also sought to identify clinical correlates of ApoE genotype by focusing on psychiatric symptoms associated with AD. Behavioral abnormalities contribute to the distress of both $\mathrm{AD}$ patients and caregivers (Teri, 1997) and are a significant cause of institutionalization (Bianchetti et al, 1995). Previous studies of psychiatric disturbances in $\mathrm{AD}$ in relation to $\mathrm{ApoE}$ have yielded a wide range of results. However, the most frequent positive 
association has been between $\varepsilon 4$ and psychotic symptoms (delusions or hallucinations). Fourteen previous studies have examined psychotic symptoms, and five have reported that 84 increased the risk for psychosis (Ramachandran et al, 1996; Ballard et al, 1997; Harwood et al, 1999; Weiner et al, 1999; Scarmeas et al, 2002), whereas nine have found no effect of $\varepsilon 4$ (Lehtovirta et al, 1996a; Cacabelos et al, 1997; Lopez et al, 1997; Lyketsos et al, 1997; Hirono et al, 1998, 1999; Levy et al, 1999; Gabryelewicz et al, 2002; Sweet et al, 2002). Sources of variation among these studies are unclear, but may include differences in patient populations, psychosis criteria, and statistical methods.

The present study was thus designed to clarify the influence of the ApoE $\varepsilon 4$ allele on the presence of psychotic symptoms in $\mathrm{AD}$. We hypothesized that $\varepsilon 4+\mathrm{AD}$ patients would manifest symptoms of psychosis more frequently and severely than 84 - patients. We also conducted an exploratory analysis to examine the association between $\varepsilon 4$ and other behavioral symptoms.

\section{MATERIALS AND METHODS}

\section{Subjects}

The study sample comprised 266 patients who met NINCDS-ADRDA criteria for probable AD (McKhann et al, 1984). Five of these patients have subsequently died and had autopsy confirming definite AD (Mirra et al, 1991). All patients enrolled in a study of phenotypic correlates of ApoE 84 in $\mathrm{AD}$ and were initially evaluated in the Yale Alzheimer's Disease Research Unit between May 1995 and August 2003. The demographics and clinical characteristics of patients are displayed in Table 1. The racial composition of the sample was: European-American $(n=259 ; 97.4 \%)$, African-American $(n=3 ; 1.1 \%)$, and Hispanic $(n=4 ; 1.5 \%)$.

All patients underwent a comprehensive evaluation by a research physician and ancillary staff, including cognitive assessment, medical history, physical and neurological examinations, serum chemistries, thyroid function studies, complete blood count, $B_{12}$, folate, VDRL, urinalysis, electrocardiogram, and brain MRI or CT. Subjects were excluded for any neurological or medical disorder (other than $\mathrm{AD}$ ) that could produce cognitive deterioration or for significant psychiatric illness (prior to the onset of cognitive impairment), alcohol, or substance abuse. Some medications received by subjects at the time of evaluation - in particular, cholinesterase inhibitors, high-dose vitamin E ( $\geqslant 400$ IU daily), and psychotropic drugs - may potentially have impacted behavioral variables analyzed in this study. These treatments were assumed to be independently distributed with regard to ApoE genotype; however, this assumption was also tested statistically (See below).

Table I AD Subject Characteristics

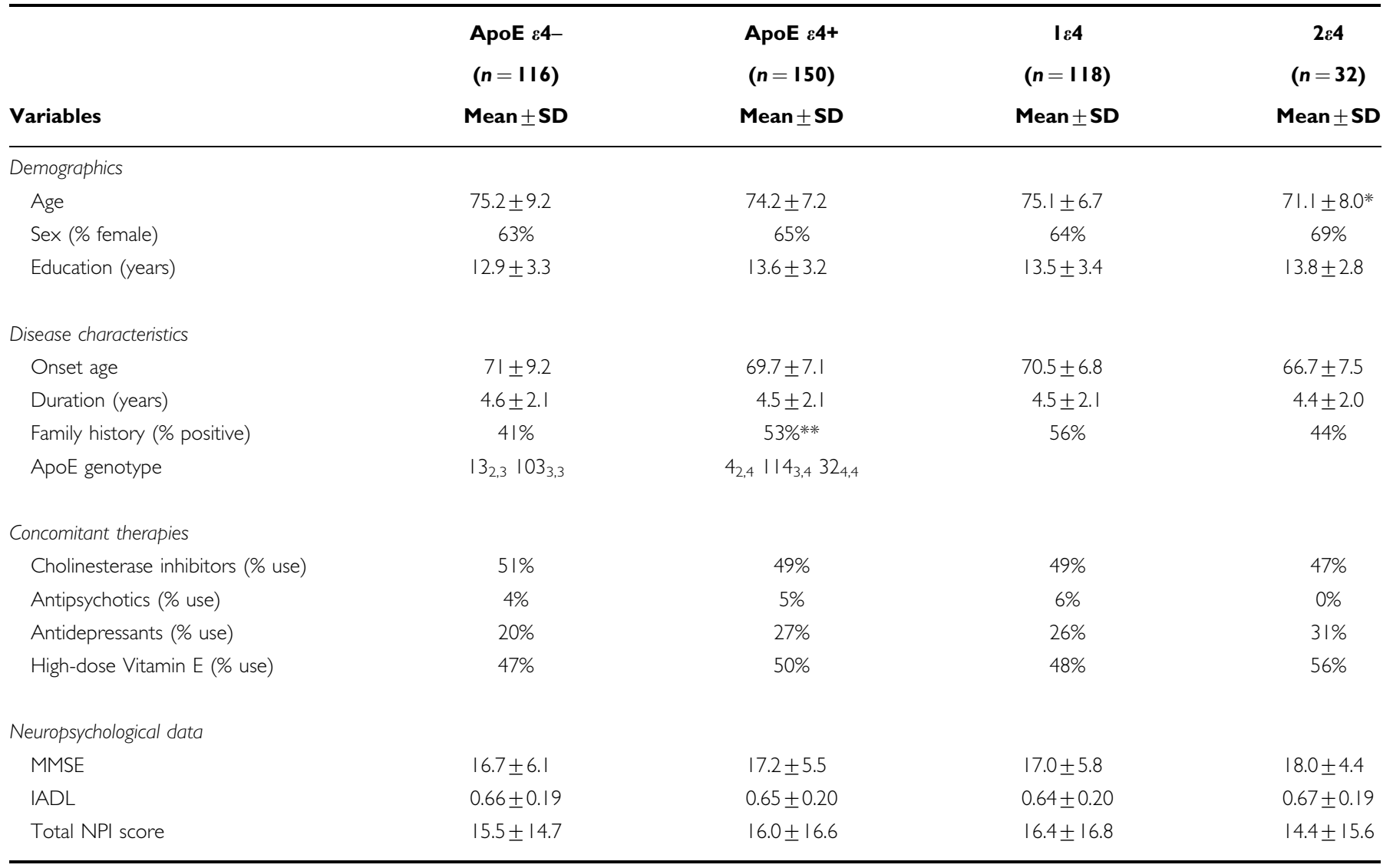

Note: MMSE: mini-mental state examination; IADL: instrumental activities of daily living (IADL); NPI: neuropsychiatric inventory.

*2 $\varepsilon 4$ group differs from I, $\varepsilon 4$ and $\varepsilon 4-$ group, $P<0.05$.

*** $\varepsilon 4+$ group differs from $\varepsilon 4-$ group, $P<0.05$. 
Family history of AD was assessed using the Alzheimer Dementia Risk Questionnaire (Breitner and Folstein, 1984) and the Dementia Questionnaire (Silverman et al, 1986) and was considered to be positive if at least one first-degree relative met criteria for primary degenerative dementia. No cases suggestive of autosomal dominant transmission were identified. Additionally, each subject was evaluated for an approximate date of disease onset, based on careful review of his or her medical records and detailed interviews with one or more primary caregivers. The date of onset was operationally defined as the date at which the 'earliest definite AD symptom' appeared. All subjects (or their responsible next of kin) provided written informed consent and were studied under a protocol approved by the Yale Human Investigation Committee.

\section{Neuropsychiatric Evaluation}

All subjects were evaluated for behavioral and psychological symptoms using the Neuropsychiatric Inventory (NPI), a structured interview that assessed the frequency and severity of these symptoms (Cummings et al, 1994). Using scripted questions, a caregiver was asked whether the patient's behavior had changed after the onset of dementia and whether the altered behavior had been present during the month preceding the evaluation. This format therefore distinguished between psychiatric symptoms that may have been present before the onset of dementia, and those that emerged during the disease process. The NPI assessed the following behavioral domains: delusions, hallucinations, agitation, depression, anxiety, elation, apathy, disinhibition, irritability, aberrant motor behavior, sleep disturbances and eating disturbances. Specific follow-up questions were used to confirm the presence of symptoms that were reported positive. For each domain in which symptoms were confirmed, the caregiver was asked to score the frequency with which symptoms occurred as: occasionally (1), often (2), frequently (3) or very frequently (4). The caregiver was asked also to score the severity of disturbances as: mild (1), moderate (2) or marked (3). Domains absent of disturbances were scored as 0 . The product of the frequency and severity score was determined for each positive item (range $=1-12$ ), and the sum of all item scores yielded the total NPI score. Possible scores ranged from 0 (no behavioral disturbances) to 144 (all behavioral disturbances maximally present).

Cognitive performance was assessed by the Mini Mental State Examination (MMSE) (Folstein et al, 1975). The functional capacity of subjects in ADLs was assessed using the Instrumental Activities of Daily Living (IADL) questionnaire (Lawton and Brody, 1969). The IADL questionnaire evaluated everyday functioning along eight domains, such as driving and using the telephone (Lawton and Brody, 1969). A score of 1 for a given domain indicated no impairment, with higher scores denoting greater degrees of impairment. As not all domains were valid for all subjects (eg men who never did laundry before AD onset), the IADL score was calculated as the sum of individual activity scores divided by the total possible number of points valid for that subject. The range of scores was therefore 0.27 (no impairment) to 1.00 (maximal impairment). All subject data were obtained by trained raters who were unaware of the subjects' ApoE genotypes.

\section{Determination of ApoE Genotype}

DNA was prepared from whole blood in the laboratory of JG by standard procedures. Genotypes were obtained by the polymerase chain reaction (PCR) - restriction fragment length polymorphism method (Hixson and Vernier, 1990) using a PCR procedure slightly modified from Tsai et al (1994). The PCR product was digested by HhaI (New England Biolabs) and subjected to electrophoresis in 5\% MetaPhor agarose (FMC Corp., Rochland, ME). Gels were stained with ethidium bromide and DNA visualized by UV transillumination. The three alleles were scored as described by Hixson and Vernier (1990). Genotypes (8\%) were repeated as a quality check, with complete concordance.

\section{Statistical Analysis}

Subject characteristics (including demographics, disease characteristics, and concomitant therapies) were compared between ApoE $\varepsilon 4+$ and $\varepsilon 4-$ patients using Student's $t$-test for continuous variables or $\chi^{2}$ analysis for dichotomous variables. We hypothesized that $84+$ patients would manifest symptoms of psychosis more frequently and more severely than $84-$ patients. We therefore calculated a psychosis rating for each subject by summing the Hallucinations and Delusions items on the NPI. The range of possible NPI-derived psychosis (NPI-Psychosis) scores was 0 to 24. As a result of the skewed distribution of NPIPsychosis scores, these were dichotomized with scores $\geqslant 1$ indicating the presence of psychosis. The association between $\varepsilon 4$ and psychosis was analyzed using a multiple logistic regression model, with psychosis as dependent variable and the following independent variables (in addition to $\varepsilon 4$ allele carrier status): age, sex, educational attainment, and MMSE as a measure of disease severity.

We performed a number of post hoc exploratory analyses. To ascertain whether our results were dependent on a particular definition of psychosis, we repeated the multiple logistic regression analysis using two progressively more restrictive criteria that have been utilized for entry into trials of antipsychotic drug for patients with dementia: (1) score $\geqslant 3$ on either the Delusions or Hallucinations item of the NPI, corresponding with moderate severity or frequency (Street et al, 2000); (2) NPI-Psychosis $\geqslant 6$ (Deberdt et al, 2005). We also examined the effect of four concomitant medication classes on psychotic symptoms by simultaneously adding them as independent variables to the primary logistic regression analysis. Furthermore, to determine whether the effect of $\varepsilon 4$ on psychosis related to a particular stage of disease, we repeated the multiple logistic regression analyses separately for the same three severity strata (mild: MMSE $\geqslant 20$, moderate: MMSE 12-19, severe: MMSE $<12$ ) analyzed by Harwood et al (1999).

Finally, we conducted an exploratory analysis of the possible role of ApoE $\varepsilon 4$ in promoting other behavioral disturbances in $\mathrm{AD}$ as measured by total NPI score and all 12 subscores. The distribution of total NPI scores in our sample showed a strong positive skew, so a Mann-Whitney $U$-test was employed to determine if $\varepsilon 4+$ and $\varepsilon 4-$ groups 
differed in total NPI score. Potential associations between the presence of $\varepsilon 4$ and the presence of symptoms in each individual NPI domain were examined by logistic regression analyses, using the same independent variables as described for NPI-Psychosis. No correction for multiple comparisons was used in this exploratory analysis.

\section{RESULTS}

\section{Subject Characteristics}

Table 1 summarizes AD subject characteristics as a function of ApoE $\varepsilon 4$ status with regard to demographics, disease characteristics, concomitant treatments, and neuropsychological data. ApoE $\varepsilon 4+$ and $\varepsilon 4-$ patients did not differ significantly in age $\left(t_{264}=0.94, P=0.35\right)$, sex distribution $\left(\chi^{2}=0.16, \mathrm{df}=1, \quad P=0.69\right)$, or educational attainment $\left(t_{264}=-1.73, P=0.085\right)$. With regard to disease characteristics, they also did not differ in age of onset $\left(t_{264}=0.82\right.$, $P=0.41)$ or duration of symptoms $\left(t_{264}=0.48, P=0.63\right)$. However, $\varepsilon 4+$ patients had a higher frequency of positive family history of $\operatorname{AD}\left(\chi^{2}=4.31, \mathrm{df}=1, P=0.038\right)$. Finally, $\varepsilon 4$ + and $\varepsilon 4-$ patients did not differ in terms of current use of cholinesterase inhibitors $\left(\chi^{2}=0.13, \mathrm{df}=1, P=0.72\right)$, antipsychotics $\left(\chi^{2}=0.019, \mathrm{df}=1, P=0.89\right)$, antidepressants $\left(\chi^{2}=2.02, \quad \mathrm{df}=1, \quad P=0.16\right)$, and high-dose Vitamin $\mathrm{E}$ $\left(\chi^{2}=0.18, \mathrm{df}=1, P=0.68\right)$.

\section{Effect of ApoE 84 Allele on Psychotic Symptoms}

Table 2 displays the frequency of psychotic symptoms (according to different criteria) in the AD patients according to ApoE $\varepsilon 4$ status. When psychosis was defined by an NPIPsychosis score $\geqslant 1$, the presence of $\varepsilon 4$ was significantly associated with psychosis (odds ratio $(\mathrm{OR})=1.87,95 \%$ $\mathrm{CI}=1.07-3.29, P=0.029)$ in a multiple logistic regression model, adjusting for the following variables: age $(\mathrm{OR}=1.05$, 95\% CI $=1.01-1.09, \quad P=0.008)$, educational attainment $(\mathrm{OR}=0.94,95 \% \mathrm{CI}=0.86-1.03, P=0.17)$, sex $(\mathrm{OR}=1.37$, $95 \% \mathrm{CI}=0.75-2.49, P=0.31)$, and MMSE score $(\mathrm{OR}=0.92$, 95\% CI $=0.88-0.97, P=0.001)$.

Post hoc analyses were conducted to examine more restrictive definitions of psychosis, using the same independent variables in the logistic regression model (Table 2). When psychosis was alternatively defined by a score $\geqslant 3$ on either the Delusions or Hallucinations item of the NPI
(Street et al, 2000), the presence of $\varepsilon 4$ was still associated with psychosis $(\mathrm{OR}=2.10,95 \% \mathrm{CI}=1.11-3.99, P=0.020)$. When psychosis was instead defined by NPI-Psychosis score $\geqslant 6$ (Deberdt et al, 2005), the presence of $\varepsilon 4$ was significantly associated with psychosis $(\mathrm{OR}=2.45,95 \%$ $\mathrm{CI}=1.21-4.98, P=0.013)$.

Although the four aforementioned classes of concomitant medications appeared randomly distributed with regard to ApoE $\varepsilon 4$ status, we also conducted a post hoc exploratory analysis of the effect of these drug classes on psychotic symptoms by simultaneously adding them as independent variables to the logistic regression analysis. Not surprisingly, current antipsychotic use was positively associated with presence of psychotic symptoms (OR=4.47, 95\% $\mathrm{CI}=1.00-19.92, P=0.049)$, but antidepressant and Vitamin $\mathrm{E}$ use were not (data not shown). Interestingly, current cholinesterase inhibitor use was negatively associated with the presence of psychotic symptoms in the logistic regression model $(\mathrm{OR}=0.51,95 \% \mathrm{CI}=0.28-0.95, P=0.03)$. Although this effect is best studied in randomized trials of cholinesterase inhibitors (Wynn and Cummings, 2004), our data lend further support to the notion that these drugs may favorably impact psychotic symptoms (Cummings and Kaufer, 1996; Wynn and Cummings, 2004).

To determine whether the effect of $\varepsilon 4$ status on psychosis was specific to a particular stage of disease, we performed an additional post hoc analysis in which we repeated the multiple logistic regression analyses separately for the same three severity strata (mild: MMSE $\geqslant 20, n=103$; moderate: MMSE $12-19, n=121$; severe: $M M S E<12, n=42$ ) analyzed by Harwood et al (1999). The results of that analysis are displayed in Figure 1. Only at the severe stage was the presence of $\varepsilon 4$ significantly associated with psychosis $(\mathrm{OR}=16.61,95 \% \mathrm{CI}=2.11-130.51, P=0.008)$, but not at the mild $(\mathrm{OR}=1.03,95 \% \mathrm{CI}=0.39-2.76, P=0.95)$ or moderate $(\mathrm{OR}=1.65,95 \% \mathrm{CI}=0.74-3.68, P=0.22)$ stages.

\section{Effect of ApoE 84 Allele on Other Behavioral Disturbances}

Exploratory analyses were also conducted for the effect of ApoE $\varepsilon 4$ on other behavioral disturbances. No differences were found between $\varepsilon 4+$ and $\varepsilon 4-\mathrm{AD}$ patients in total NPI score $(Z=-0.302, P=0.76$, Mann-Whitney $U$-test). With regard to individual NPI symptom subscores (Table 3),

Table 2 Frequency of Psychosis in AD Patients According to ApoE $\varepsilon 4$ Status

\begin{tabular}{|c|c|c|c|c|c|c|c|c|c|c|c|}
\hline \multirow[b]{2}{*}{ Criterion } & \multicolumn{2}{|c|}{$\begin{array}{l}\text { ApoE } \varepsilon 4-(n=116) \\
\text { frequency }\end{array}$} & \multicolumn{2}{|c|}{$\begin{array}{c}\text { ApoE } \varepsilon 4+(n=150) \\
\text { frequency }\end{array}$} & \multirow[b]{2}{*}{ OR } & \multirow[b]{2}{*}{$95 \% \mathrm{Cl}$} & \multirow[b]{2}{*}{$P$} & \multicolumn{2}{|c|}{$\begin{array}{c}\text { I } \varepsilon 4(n=\mid \text { I I }) \\
\text { frequency }\end{array}$} & \multicolumn{2}{|c|}{$\begin{array}{c}2 \varepsilon 4(n=32) \\
\text { frequency }\end{array}$} \\
\hline & $n$ & $\%$ & $n$ & $\%$ & & & & $n$ & $\%$ & $n$ & $\%$ \\
\hline NPI-Psychosis $\geqslant 1$ & 32 & 27.6 & 56 & 37.3 & 1.87 & $1.07-3.29$ & 0.029 & 44 & 37.3 & 12 & 37.5 \\
\hline $\begin{array}{l}\text { NPI Delusions } \geqslant 3 \\
\text { or Hallucinations } \geqslant 3\end{array}$ & 23 & 19.8 & 44 & 29.3 & 2.10 & $1.13-3.94$ & 0.020 & 35 & 29.7 & 9 & 28.1 \\
\hline
\end{tabular}

Note: NPI, neuropsychiatric inventory; NPI, psychosis score was defined as the sum of scores on the 'Delusions' and 'Hallucinations' items on the NPI. OR (odds ratio) and $95 \% \mathrm{Cl}$ are for the effect of $\varepsilon 4$ carrier status in a multiple logistic regression model, with psychosis as dependent variable and the following additional independent variables: age, sex, education, and MMSE. 
84 was significantly associated with the presence of delusions $(\mathrm{OR}=2.26,95 \% \mathrm{CI}=1.24-4.13, P=0.008)$ and irritability $(\mathrm{OR}=1.75,95 \% \mathrm{CI}=1.02-3.00, P=0.041)$. In addition, nonsignificant trends were observed for associations with the presence of hallucinations $(P=0.100)$, aberrant motor behaviors $(P=0.100)$ and sleep disturbances $(P=0.076)$.

\section{DISCUSSION}

We investigated the effect of the ApoE $\varepsilon 4$ allele on the development of psychotic manifestations in AD. Using

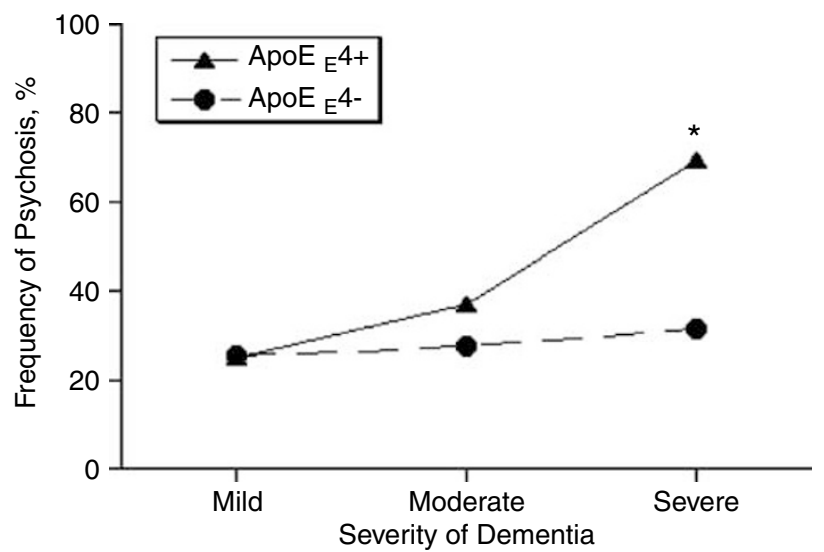

Figure I Frequency of psychosis by ApoE $\varepsilon 4$ carrier status and dementia severity. Mini Mental State Examination (MMSE) score was used to classify $A D$ patients as mild (MMSE $\geqslant 20, n=103$ ), moderate (MMSE $=12-19$, $n=121$ ), or severe $(M M S E<12, n=42)$. Separate multiple logistic regression analyses were performed for each severity category, with presence of psychosis as dependent variable and the following independent variables (in addition to $\varepsilon 4$ carrier status): age, sex, educational attainment, and MMSE. *Only at the severe stage was the presence of $\varepsilon 4$ significantly associated with psychosis (odds ratio $(O R)=|6.6|, 95 \% \mathrm{Cl}=2.1|-| 30.5 \mid$, $P=0.008)$. multiple logistic regression analyses, we found that the presence of $\varepsilon 4$ was associated with psychotic symptoms, adjusting for age, sex, education, and MMSE score. Exploratory analyses suggested that this effect accrued specifically from patients with severe-stage $\mathrm{AD}$ and primarily from an association between $\varepsilon 4$ and delusions. The $\varepsilon 4$ allele did not appear to influence the development of most other behavioral symptoms in our sample.

\section{Comparison to Other ApoE 84 AD Psychosis Studies}

As displayed in Table 4, previous studies of psychosis in $\mathrm{AD}$ in relation to ApoE have yielded a wide range of results. However, the most frequent positive association has been between 84 and psychotic symptoms. Fifteen studies (including the present one) have examined psychotic symptoms, and six (including the present one) have reported that 84 increased the risk for psychosis (Ramachandran et al, 1996; Ballard et al, 1997; Harwood et al, 1999; Weiner et al, 1999; Scarmeas et al, 2002), whereas nine have found no effect of $\varepsilon 4$ (Lehtovirta et al, 1996a; Cacabelos et al, 1997; Lopez et al, 1997; Lyketsos et al, 1997; Hirono et al, 1998, 1999; Levy et al, 1999; Gabryelewicz et al, 2002; Sweet et al, 2002). Among the six positive studies only two others (Weiner et al, 1999; Scarmeas et al, 2002) have considered delusions and hallucinations separately. Our exploratory finding that 84 was preferentially associated with delusions was shared by Scarmeas et al (2002) who observed that $\varepsilon 4$ was associated specifically with an increased risk for delusions in a dose dependent manner, whereas 84 homozygotes actually had a reduced risk for hallucinations. By contrast, Weiner et al (1999) reported marginal $(P=0.05)$ positive associations between $\mathrm{ApoE} \varepsilon 4$ and both delusions and hallucinations. This may reflect a statistical power issue, since delusions are more prevalent among $\mathrm{AD}$ patients than hallucinations (Hirono et al, 1998; Bassiony and Lyketsos, 2003), including in our present sample

Table 3 Frequency of Neuropsychiatric Symptoms in AD Patients According to ApoE $\varepsilon 4$ Status

\begin{tabular}{|c|c|c|c|c|c|c|c|c|c|c|c|}
\hline \multirow[b]{2}{*}{ NPI subscore } & \multicolumn{2}{|c|}{$\begin{array}{c}\text { ApoE } \varepsilon 4-(n=116) \\
\text { frequency }\end{array}$} & \multicolumn{2}{|c|}{$\begin{array}{l}\text { ApoE } \varepsilon 4+(n=150) \\
\text { frequency }\end{array}$} & \multirow[b]{2}{*}{ OR } & \multirow[b]{2}{*}{$95 \% \mathrm{Cl}$} & \multirow[b]{2}{*}{$P$} & \multicolumn{2}{|c|}{$\begin{array}{c}\text { I } \varepsilon 4(n=|| 18) \\
\text { frequency }\end{array}$} & \multicolumn{2}{|c|}{$\begin{array}{c}2 \varepsilon 4(n=32) \\
\text { frequency }\end{array}$} \\
\hline & $n$ & $\%$ & $n$ & $\%$ & & & & $n$ & $\%$ & $n$ & $\%$ \\
\hline Delusions & 26 & 22.4 & 51 & 34.0 & 2.26 & $1.24-4.13$ & 0.008 & 41 & 34.7 & 10 & 31.3 \\
\hline Hallucinations & 14 & 12.1 & 27 & 18.0 & 1.84 & $0.89-3.80$ & 0.100 & 22 & 18.6 & 5 & 15.6 \\
\hline Depression & 41 & 35.3 & 48 & 32.0 & 0.87 & $0.52-1.46$ & 0.596 & 36 & 30.5 & 12 & 37.5 \\
\hline Elation & 11 & 9.5 & 8 & 5.3 & 0.60 & $0.23-1.55$ & 0.289 & 6 & 5.1 & 2 & 6.3 \\
\hline Apathy & 50 & 43.1 & 58 & 38.7 & 0.87 & $0.52-1.43$ & 0.576 & 48 & 40.7 & 10 & 31.3 \\
\hline Disinhibition & 29 & 25.0 & 26 & 17.3 & 0.69 & $0.38-1.26$ & 0.226 & 23 & 19.5 & 3 & 9.4 \\
\hline Irritability & 31 & 26.7 & 56 & 37.3 & 1.75 & $1.02-3.00$ & 0.041 & 49 & 41.5 & 7 & 21.9 \\
\hline
\end{tabular}

Note: NPI, neuropsychiatric inventory. OR (odds ratio) and $95 \% \mathrm{Cl}$ are for the effect of $\varepsilon 4$ carrier status in multiple logistic regression models, with NPI subscores as dependent variables and the following additional independent variables: age, sex, education, and MMSE. 
Table 4 Studies of Psychotic Symptoms in AD in Relation to ApoE $\varepsilon 4$ Status

\begin{tabular}{lcll}
\hline Study & Sample (n) & Measures & Effect of ApoE genotype on psychosis and other behavior \\
\hline Lehtovirta et al (1996a) & 58 & $\mathrm{Cl}$, Ham-D & No effect of genotype on psychosis or depression \\
Ramachandran et al (1996) & 46 & $\mathrm{Cl}$, Ham-D & $\varepsilon 4$ increases risk for psychosis and depression \\
Ballard et al (1997) & $5 \mathrm{I}^{\mathrm{a}}$ & $\mathrm{CDS}, \mathrm{BSC}$ & $\varepsilon 4$ elevates risk for psychosis, lowers risk for depression \\
Cacabelos et al (1997) & $207^{\mathrm{a}}$ & $\mathrm{BPAD}$, Ham-A/D, SDASDS & No effect of genotype on behavioral disturbances \\
Lopez et al (1997) & 194 & $\mathrm{Cl}, \mathrm{NE}, \mathrm{BRS}$ & No effect of genotype on psychotic symptoms \\
Lyketsos et al (1997) & 120 & $\mathrm{NE}$ & No effect of genotype on psychosis or depression \\
Hirono et al (1998) & 228 & $\mathrm{BPAD}, \mathrm{NPI}$ & No effect of genotype on psychotic symptoms \\
Weiner et al (1999) & $97^{\mathrm{b}}$ & $\mathrm{BDRS}$ & $\varepsilon 4$ marginally associated with delusions and hallucinations \\
Harwood et al (1999) & $501^{\mathrm{b}}$ & $\mathrm{Cl}, \mathrm{Ham}-\mathrm{D}$ & $\varepsilon 4$ increases risk for psychosis \\
Hirono et al (1999) & 175 & $\mathrm{NPI}$ & No effect of genotype on behavioral disturbances \\
Levy et al (1999) & $605^{\mathrm{b}}$ & $\mathrm{NPI}$ & No effect of genotype on behavioral disturbances \\
Gabryelewicz et al (2002) & 139 & $\mathrm{BPAD}$ & No effect of genotype on behavioral disturbances \\
Scarmeas et al (2002) & 87 & $\mathrm{CUSPAD}$ & $\varepsilon 4$ increases risk for delusions \\
Sweet et al (2000) & 316 & $\mathrm{BRSD}$ & Genotype does not predict time to onset of psychosis \\
Zdanys et al & 266 & $\mathrm{NPI}$ & $\varepsilon 4$ increases risk for psychosis \\
\hline
\end{tabular}

Studies in bold report a positive association between ApoE $\varepsilon 4$ and psychotic symptoms in AD.

Abbreviations: Clinical interview with primary caregiver (Cl), Hamilton Depression Rating Scale (Ham-D), Cornell Depression Scale (CDS), Burns symptom checklist for psychosis (BSC), Behavioral Pathology in Alzheimer's Disease Rating Scale (BPAD), Hamilton Anxiety Rating Scale (Ham-A), Senile Dementia-Associated Sleep Disorders Scale (SDASDS), Neuropsychiatric examination of patient (NE), Behavior Rating Scale (BRS), Neuropsychiatric Inventory (NPI), Blessed Dementia Rating Scale (BDRS), Columbia University Scale for Psychopathology in Alzheimer's Disease (CUSPAD), Consortium to Establish a Registry for AD Behavioral Rating Scale for Dementia (BRSD).

aSample included subjects with dementia other than AD.

${ }^{b}$ Sample included subjects with possible and probable AD diagnoses.

(delusions $29 \%$, hallucinations $15 \%$ ). Two recent studies have used Cox proportional hazards analysis to determine whether ApoE 84 influences time to onset of psychosis in patients followed longitudinally, but have reported discrepant results (Scarmeas et al, 2002; Sweet et al, 2002). Sources of variation among these fifteen studies are several, but particularly include differences in psychosis criteria, subject severity, and method of analyzing ApoE $\varepsilon 4$ status.

Psychosis criteria. Previous studies have used a variety of methods to identify psychotic symptoms in their subjects, including general clinical examination (Lehtovirta et al, 1996a; Lyketsos et al, 1997; Hirono et al, 1999), rating scales (Ballard et al, 1997; Cacabelos et al, 1997; Hirono et al, 1998; Levy et al, 1999; Weiner et al, 1999; Gabryelewicz et al, 2002; Scarmeas et al, 2002), or a combination (Ramachandran et al, 1996; Lopez et al, 1997; Sweet et al, 2002). Those studies that have employed research rating scales have used a wide range of scales (see Table 4), making it difficult to reconcile discrepant reports. Our choice of the NPI has a number of advantages and limitations, some of which derive from its reliance on caregiver interview (Cummings et al, 1994). One advantage of the NPI is that it yields a quantitative measure of psychosis based on frequency and severity of symptoms. Although our quantitative NPI scores exhibited too much skew to analyze as continuous variables with parametric statistics, they nonetheless permitted us to consider different thresholds of severity. Virtually all studies to date have considered only presence or absence of psychosis. However, when we alternatively considered two more restrictive thresholds of clinically significant psychosis from the NPI - that have been used as criteria for entry into clinical trials of antipsychotic drugs (Street $e t$ al, 2000; Deberdt et al, 2005) — we found essentially the same results. These analyses suggest that our findings did not depend heavily on the criterion employed to classify $\mathrm{AD}$ subjects as psychotic.

Subject severity. Given the well-documented increase in psychotic symptoms with AD severity (Lopez et al, 1997; Hirono et al, 1998; Harwood et al, 1999; Gabryelewicz et al, 2002), variations in subject disease stage may represent an important difference among studies. Harwood et al (1999), observed that the elevated risk for psychosis was present specifically at the severe stage (MMSE $<12$ ) of cognitive impairment among $\mathrm{AD}$ patients carrying the $\varepsilon 4$ allele. When we stratified our sample using the same cutpoints as Harwood et al, we also found that the 84 effect was statistically significant only for the severe-stage patients (Figure 1). Consequently an association between ApoE $\varepsilon 4$ and psychotic symptoms may not be detected by studies that include only (eg Levy et al, 1999) or predominantly (eg Hirono et al, 1999) mild-to-moderate stage patients. Although several studies do not provide clear description of the severity range of their subject samples, two other positive studies either included severe-stage patients (Weiner et al, 1999) or followed patients longitudinally into the severe stage (Scarmeas et al, 2002). Discrepant results are not accounted for entirely by differences in patient severity, however, as one positive study was restricted to mild-to-moderate stage patients (Ramachandran et al, 1996), and two negative studies enrolled large numbers of severe-stage patients (Cacabelos et al, 1997; Gabryelewicz et al, 2002). 
ApoE $\& 4$ carrier status vs dose. Although we chose to evaluate ApoE $\& 4$ carrier status dichotomously, several other studies have examined the number or 'dose' of $\varepsilon 4$ alleles in association with psychotic symptoms, including two of the positive studies (Weiner et al, 1999; Scarmeas et al, 2002). Among the six positive studies only Scarmeas et al, 2002 reported a full dose effect of $\varepsilon 4 \quad(2 \varepsilon 4>1 \varepsilon 4>0 \varepsilon 4)$ on psychotic symptoms in $\mathrm{AD}$. If we alternatively entered $\varepsilon 4$ allele number (instead of carrier status) in our multiple logistic regression model, we would still find that $\varepsilon 4$ number was significantly associated with psychosis $(\mathrm{OR}=1.60,95 \%$ $\mathrm{CI}=1.07-2.42, P=0.024)$. However, we would not observe a full dose effect, as the $1 \varepsilon 4$ and $2 \varepsilon 4$ groups would not differ in the presence of psychotic symptoms (Table 2).

An important additional limitation of the present study- and of ApoE psychosis studies broadly-pertains to selection bias, with regard to ethnicity, disease severity, and particularly, the range of psychotic symptoms included. Our subjects tended to be recruited from those participating in other research protocols, some of which specifically selected against antipsychotic drug use (thus the low rate of antipsychotic drug use $=5 \%)$. The overall prevalence of psychosis in our study (33\%) is comparable to other similar studies buy likely underestimates the true population prevalence. Population-based studies that include institutionalized patients would be valuable to confirm our results across the full spectrum of dementia severity.

\section{Interpretation of an Increased Risk of Psychosis in ApoE $84+$ AD}

The mechanism by which ApoE $\varepsilon 4$ may increase the risk for psychotic symptoms in $\mathrm{AD}$ is unclear. Although the $\varepsilon 4$ allele has been shown to promote the neuropathological features of $\mathrm{AD}$, including $\beta$-amyloid $(\mathrm{A} \beta$ ) deposition (Schmechel et al, 1993; Nagy et al, 1995; Norrman et al, 1995; GomezIsla et al, 1996) and neurofibrillary tangle formation (Schmechel et al, 1993; Nagy et al, 1995; Norrman et al, 1995; Gomez-Isla et al, 1996), attempts to relate these features to psychotic symptoms in $\mathrm{AD}$ have yielded conflicting results (Zubenko et al, 1991; Förstl et al, 1994; Mukaetova-Ladinska et al, 1995; Sweet et al, 2000). Additionally, ApoE $\varepsilon 4$ has been linked with more profound cholinergic loss in the frontal cortex (Soininen et al, 1995) and medial temporal lobe (Poirier et al, 1995), and acetylcholine levels have in turn been implicated in psychotic disturbances in AD (Cummings and Kaufer, 1996). Neuroimaging studies may shed additional light on the association between ApoE 84 and psychotic manifestations of $\mathrm{AD}$. One in vivo SPECT study has suggested that delusions in $\mathrm{AD}$ may be associated with hypoperfusion in the temporal lobes (Starkstein et al, 1994), and some (Lee et al, 2003) but not all (van Dyck et al, 1998) functional imaging studies have shown that $\mathrm{AD}$ patients who carry the $\varepsilon 4$ allele have reduced temporal lobe function. The structural MRI literature is more unified in showing greater medial temporal lobe atrophy in association with the $\varepsilon 4$ allele in AD (Lehtovirta et al, 1996b; Hashimoto et al, 2001; Basso et al, in press).

In conclusion, $\mathrm{AD}$ patients who carry the $\mathrm{ApoE} \varepsilon 4$ allele are at greater risk than noncarriers for developing psychotic symptoms, particularly delusions. This effect appears to be associated specifically with the severe stages of the disease. Although an association has been made between the ApoE $\varepsilon 4$ genotype and psychosis in $\mathrm{AD}$, more research must be conducted to examine the pathological links between the gene and the symptom.

\section{ACKNOWLEDGEMENTS}

The authors thank Ann Marie Lacobelle for technical assistance. This research was supported by the Alzheimer's Association IIRG-01-2891 (CHvD), the National Alliance for Research on Schizophrenia and Affective Disorders (CHvD), NIH Clinical Neuroscience Mental Health Research Training Grant, K24-DA15105 (JG), and P30-MH30929.

\section{REFERENCES}

Aerssens J, Raeymaekers P, Lilienfeld S, Geerts H, Konings F, Parys $\mathrm{W}$ (2001). APOE genotype: No influence on galantamine treatment efficacy nor on rate of decline in Alzheimer's Disease. Dement Geriatr Cogn Disord 12: 69-77.

Ballard C, Massey H, Lamb H, Morris C (1997). Apolipoprotein E: non-cognitive symptoms and cognitive decline in late-onset Alzheimer's disease. J Neurol Neurosurg Psychiatr 63: 273-274.

Bassiony MM, Lyketsos CG (2003). Delusions and hallucinations in Alzheimer's disease: review of the brain decade. Psychosomatics 44: 388-401.

Basso M, Gelernter J, Yang J, MacAvoy MG, Varma P, Bronen RA et al (in press). Apolipoprotein E epsilon4 is associated with atrophy of the amygdala in Alzheimer's disease. Neurobiol Aging.

Bianchetti A, Scuratti A, Zanetti O, Binetti G, Frisoni GB, Magni E et al (1995). Predictors of mortality and institutionalization in Alzheimer disease patients 1 year after discharge from an Alzheimer dementia unit. Dementia 6: 108-112.

Breitner JCS, Folstein MF (1984). Familial Alzheimer's disease: a prevalent disorder with specific clinical features. Psychol Med 14: 63-80.

Cacabelos R, Rodriguez B, Carrera C, Beyer K, Lao JI, Sellers MA (1997). Behavioral changes associated with different apolipoprotein E genotypes in dementia. Alzheimer Dis Assoc Disord 11: S27-S34.

Corder EH, Saunders AM, Strittmatter WJ, Schmechel DE, Gaskell PC, Small GW et al (1993). Gene dose of apolipoprotein E type 4 allele and the risk of Alzheimer's disease in late onset families. Science 261: 921-923.

Craft S, Teri L, Edland SD, Kukull WA, Schellenberg G, McCormick WC et al (1998). Accelerated decline in apolipoprotein E-e4 homozygotes with Alzheimer's disease. Neurology 51: 149-153.

Cummings JL, Kaufer DI (1996). Neuropsychiatric aspects of Alzheimer's disease: the cholinergic hypothesis revisited. Neurology 47: 876-883.

Cummings JL, Mega M, Gray K, Rosenberg-Thompson S, Carusi DA, Gornbein J (1994). The neuropsychiatric inventory: comprehensive assessment of psychopathology in dementia. Neurology 44: 2308-2314.

Deberdt WG, Dysken MW, Rappaport SA, Feldman PD, Young CA, Hay DP et al (2005). Comparison of olanzapine and risperidone in the treatment of psychosis and associated behavioral disturbances in patients with dementia. Am J Geriatr Psychiatr 13: $722-730$.

Farlow MR, Cyrus PA, Nadel A, Lahiri DK, Brashear A, Gulanski B (1999). Metrifonate treatment of AD-Influence of APOE genotype. Neurology 53: 2010-2016.

Farrer LA, Cupples LA, Haines JL, Hyman BT, Kukull WA, Mayeux $\mathrm{R}$ et al (1997). Effects of age, sex and ethnicity on the association 
between apolipoprotein $\mathrm{E}$ genotype and Alzheimer disease-A meta-analysis. JAMA 278: 1349-1356.

Folstein MF, Folstein SE, McHugh PR (1975). Mini-mental state': a practical method for grading the cognitive state of patients for the clinician. J Psychiatr Res 12: 189-198.

Förstl H, Burns A, Levy R, Cairns N (1994). Neuropathological correlates of psychotic phenomena in confirmed Alzheimer's disease. Br J Psychiatr 165: 53-59.

Frisoni GB, Govoni S, Geroldi C, Bianchetti A, Calabresi L, Franceschini G et al (1995). Gene dose of the e4 allele of apolipoprotein $\mathrm{E}$ and disease progression in sporadic late-onset Alzheimer's disease. Ann Neurol 37: 596-604.

Gabryelewicz T, Religa D, Styczynska M, Peplonska B, Pfeffer A, Wasiak B et al (2002). Behavioural pathology in Alzheimer's disease with special reference to apolipoprotein E genotype. Dement Geriatr Cogn Disord 14: 208-212.

Gomez-Isla T, West HL, Rebeck GW, Harr SD, Growdon JH, Locascio JJ et al (1996). Clinical and pathological correlates of apolipoprotein E e4 in Alzheimer's disease. Ann Neurol 39: 62-70.

Harwood DG, Barker WW, Ownby RL, St. George-Hyslop PH, Duara R (1999). Apolipoprotein-E (APO-E) genotype and symptoms of psychosis in Alzheimer's disease. Am J Geriatr Psychiatr 7: 119-123.

Hashimoto M, Yasuda M, Tanimukai S, Matsui M, Hirono N, Kazui $\mathrm{H}$ et al (2001). Apolipoprotein $\mathrm{E}$ epsilon 4 and the pattern of regional brain atrophy in Alzheimer's disease. Neurology 57: 1461-1466.

Hirono N, Hashimoto M, Yasuda M, Kazui H, Mori E (2003). Accelerated memory decline in Alzheimer's disease With Apolipoprotein epsilon4 allele. J Neuropsychiatry Clin Neurosci 15: 354-358.

Hirono N, Mori E, Yasuda M, Ikejiri Y, Imamura T, Shimomura T et al (1998). Factors associated with psychotic symptoms in Alzheimer's disease. J Neurol Neurosurg Psychiatr 64: 648-652.

Hirono N, Mori E, Yasuda M, Imamura T, Shimomura T, Hashimoto $M$ et al (1999). Lack of effect of apolipoprotein $\mathrm{E}$ E4 allele on neuropsychiatric manifestations in Alzheimer's disease. J Neuropsychiatry Clin Neurosci 11: 66-70.

Hixson JE, Vernier DT (1990). Restriction isotyping of human apolipoprotein $\mathrm{E}$ by gene amplification and cleavage with HhaI. J Lipid Res 31: 545-548.

Kleiman T, Zdanys K, Black B, Rightmer T, Grey M, Garman K et al (2006). Apolipoprotein $\mathrm{E} \mathrm{e} 4$ is unrelated to cognitive or functional decline in Alzheimer's Disease: Retrospective and prospective analysis. Dement Geriatr Cogn Disord 22: 73-82.

Lawton MP, Brody EM (1969). Assessment of older people: selfmaintaining and instrumental activities of daily living. Gerontologist 9: 179-186.

Lee KU, Lee JS, Kim KW, Jhoo JH, Lee DY, Yoon JC et al (2003). Influence of the apolipoprotein E type 4 allele on cerebral glucose metabolism in Alzheimer's disease patients. I Neuropsychiatry Clin Neurosci 15: 78-83.

Lehtovirta M, Soininen H, Helisalmi S, Mannermaa A, Helkala E-L, Hartikainen $\mathrm{P}$ et al (1996a). Clinical and neuropsychological characteristics in familial and sporadic Alzheimer's disease: Relation to apolipoprotein E polymorphism. Neurology 46: 413-419.

Lehtovirta M, Soininen H, Laakso MP, Partanen K, Helisalmi S, Mannermaa A et al (1996b). SPECT and MRI analysis in Alzheimer's disease: relation to apolipoprotein E e4 allele. J Neurol Neurosurg Psychiatr 60: 644-649.

Levy ML, Cummings JL, Fairbanks LA, Sultzer DL, Small GW (1999). Apolipoprotein E genotype and noncognitive symptoms in Alzheimer's disease. Biol Psychiatr 45: 422-425.

Lopez OL, Kamboh MI, Becker JT, Kaufer DI, DeKosky ST (1997). The apolipoprotein E e4 allele is not associated with psychiatric symptoms or extrapyramidal signs in probable Alzheimer's disease. Neurology 49: 794-797.
Lyketsos CG, Baker L, Warren A, Steele C, Brandt J, Steinberg M et al (1997). Depression, delusions and hallucinations in Alzheimer's Disease: No relationship to apolipoprotein E genotype. J Neuropsychiatr Clin Neurosci 9: 64-67.

McKhann G, Drachman D, Folstein M, Katzman R, Price D, Stadlan EM (1984). Clinical diagnosis of Alzheimer's disease: report of the NINCDS-ADRDA work group under the auspices of Department of Health and Human Services Task Force on Alzheimer's disease. Neurology 34: 939-944.

Mirra SS, Heyman A, McKeel D, Sumi SM, Crain BJ, Brownlee LM et al (1991). The consortium to establish a registry for Alzheimer's disease (CERAD). Part II. Standardization of the neuropathologic assessment of Alzheimer's disease. Neurology 41: 479-486.

Mukaetova-Ladinska EB, Harrington CR, Xuereb J, Roth M, Wischik CM (1995). Biochemical, neuropathological, and clinical correlations of neurofibrillary degenration in Alzheimer's disease. In: Bergener M, Finkel SI (eds). Biochemical, neuropathological, and clinical correlations of neurofibrillary degenration in Alzheimer's disease. Springer Publishing: New York. pp 57-80.

Nagy NS, Esiri MM, Jobst KA, Johnston C, Litchfield S, Sim E et al (1995). Influence of the apolipoprotein E genotype on amyloid deposition and neurofibrillary tangle formation in Alzheimer's disease. Neuroscience 69: 757-761.

Norrman J, Brookes AJ, Yates C, St. Clair D (1995). Apolipoprotein E genotype and its effect on duration and severity of early and late onset Alzheimer's disease. Br J Psychiatr 167: 533-536.

Poirier J, Delisle M-C, Quirion R, Aubert I, Farlow M, Lahiri D et al (1995). Apolipoprotein E4 allele as a predictor of cholinergic deficits and treatment outcome in Alzheimer's disease. Proc Natl Acad Sci 92: 12260-12264

Ramachandran G, Marder K, Tang M, Schofield PW, Chun MR, Devanand DP et al (1996). A preliminary study of apolipoprotein E genotype and psychiatric manifestations of Alzheimer's disease. Neurology 47: 256-259.

Saunders AM, Strittmatter WJ, Schmechel DE, St. George-Hyslop PH, Pericak-Vance MA, Joo BS et al (1993). Association of apolipoprotein E allele e4 with late-onset familial and sporadic Alzheimer's disease. Neurology 43: 1467-1472.

Scarmeas N, Brandt J, Albert M, Devanand DP, Marder K, Bell K et al (2002). Association between the APOE genotype and psychopathologic symptoms in Alzheimer's disease. Neurology 58: $1182-1188$.

Schmechel DE, Saunders AM, Strittmatter WJ, Crain B, Hulette C, Joo SH et al (1993). Increased amyloid ß-peptide deposition as a consequence of apolipoprotein E genotype in late-onset Alzheimer's disease. Proc Natl Acad Sci 90: 9649-9653.

Silverman JM, Breitner JCS, Mohs RC, Davis KL (1986). Reliability of the family history method in genetic studies of Alzheimer's disease and related dementias. Am J Psychiatr 143: $1279-1282$.

Soininen H, Kosunen O, Helisalmi S, Mannernaa A, Paljärvi L, Talasniemi S et al (1995). A severe loss of choline acetyltransferase in the frontal cortex of Alzheimer patients carrying the apolipoprotein e4 allele. Neurosci Lett 187: 79-82.

Starkstein SE, Vazquez S, Petracca G, Sabe L, Migliorelli R, Teson A et al (1994). A SPECT study of delusions in Alzheimer's disease. Neurology 44: 2055-2059.

Stern Y, Brandt J, Albert M, Jacobs DM, Liu X, Bell K et al (1997). The absence of an apolipoprotein e4 allele is associated with a more aggressive form of Alzheimer's disease. Ann Neurol 41: 615-620.

Street JS, Clark WS, Gannon KS, Cummings JL, Bymaster FP, Tamura RN et al (2000). Olanzapine treatment of psychotic and behavioral symptoms in patients with Alzheimer disease in nursing care facilities: a double-blind, randomized, placebo-controlled trial. The HGEU Study Group. Arch Gen Psychiatr 57: 968-976. 
Sweet R, Kamboh MI, Wisniewski SR, Lopez OL, Klunk WE, Kaufer DI et al (2002). Apolipoprotein E and alpha-1-antichymotrypsin genotypes do not predict time to psychosis in Alzheimer's disease. J Geriatr Psychiatr Neurol 15: 24-30.

Sweet RA, Hamilton RL, Lopez OL, Klunk WE, Wisniewski SR, Kaufer DI et al (2000). Psychotic symptoms in Alzheimer's disease are not associated with more severe neuropathologic features. Int Psychogeriatr 12: 547-558.

Teri L (1997). Behavior and caregiver burden: Behavioral problems in patients with Alzheimer disease and its association with caregiver distress. Alzheimer Dis Assoc Disord 11: S35-S38.

Tsai M-S, Tangalos EG, Petersen RC, Smith GE, Schaid DJ, Kokmen $\mathrm{E}$ et al (1994). Apolipoprotein E: risk factor for Alzheimer disease. Am J Hum Genet 54: 643-649. van Dyck CH, Gelernter J, MacAvoy MG, Avery RA, Criden M, Okereke O et al (1998). The absence of an apolipoprotein E e4 allele is associated with increased parietal rCBF asymmetry in Alzheimer's disease. Arch Neurology 55: 1460-1466.

Weiner MF, Vega G, Risser RC, Honig LS, Cullum CM, Crumpacker D et al (1999). Apolipoprotein E epsilon 4, other risk factors, and course of Alzheimer's disease. Biol Psychiatr 45: 633-638.

Wynn ZJ, Cummings JL (2004). Cholinesterase inhibitor therapies and neuropsychiatric manifestations of Alzheimer's disease. Dement Geriatr Cogn Disord 17: 100-108.

Zubenko GS, Moossy J, Martinez AJ, Rao G, Claassen D, Rosen J et al (1991). Neuropathologic and neurochemical correlates of psychosis in primary dementia. Arch Neurol 48: 619-624. 